\title{
Smoking behaviour and attitudes among adult Saudi nationals in Riyadh City, Saudi Arabia
}

\author{
Abdalla Abdel Wahid Saeed, Tawfik Ahmed Khoja, Shaista Bashir Khan
}

\begin{abstract}
Objective-To measure the smoking behaviour and attitudes among Saudi adults residing in Riyadh City, the capital of the Kingdom of Saudi Arabia.

Design-Cross-sectional survey.

Setting and subjects-Primary health care centres (PHCCs) in Riyadh City were selected by stratified random sampling. Subjects resident in each PHCC catchment area were selected by systematic sampling from their records in the PHCCs; 1534 adults aged 15 years and older were interviewed during January to April 1994.
\end{abstract}

Main outcome measures-Self-reported smoking prevalence; age of smoking initiation; daily cigarette consumption; duration of smoking; reasons for smoking, not smoking, and quitting smoking; intentions to smoke in the future; and attitudes toward various tobacco control measures. Results-25.3\% of respondents were current smokers, $10.2 \%$ were ex-smokers, and $64.5 \%$ had never smoked. About $79 \%$ of all smokers started smoking between the ages of 15 and 30 years, and $19.5 \%$ before age 15. Significantly higher smoking prevalence and daily cigarette consumption were associated with being male, single, and being more highly educated. Relief of psychological tension, boredom, and imitating others were the most important reasons for smoking, whereas health and religious considerations were the most important reasons for not smoking among never-smokers, for quitting among ex-smokers, and for attempting to quit or thinking about quitting among current smokers. About $90 \%$ of all subjects thought that they would not smoke in the future. Physicians and religious men were identified as the most effective anti-smoking advocates by a much higher proportion of respondents (44\%) than nurses, health educators, and teachers (each less than 5\%). Health and religious education were generally cited as more effective in deterring smoking than tobacco control laws and policies.

Conclusions-Cigarette smoking is prevalent among Saudi adults in Riyadh, particularly males, most of whom begin to smoke rather early in life and continue for many years. Health and religious education should be the cornerstone for any organised tobacco control activities, which are urgently needed to combat the expected future epidemic of smoking- $-\vec{\circ}$ related health problems.

(Tobacco Control 1996;5:215-219)

Keywords: smoking behaviour; health education; Saudi Arabia

Introduction

The ill effects of tobacco smoking have beenwell documented. Smoking prevalence and $\mathcal{\Phi}^{\infty}$ cigarette consumption are decreasing in many developed countries. The reverse is unfortunately happening in developing countries, where a large proportion of adult men are dependent on some form of tobacco use. ${ }^{2} \varnothing$ Tobacco use by women in developing countries is still low ${ }^{1}$ but is increasing particularly amongo educated women. ${ }^{34}$ The World Health Organisation estimates that, during the $1990 \mathrm{~s}$, , three million people will die every year from $\frac{0}{\mathbb{Q}}$ diseases caused by smoking and that about $a \stackrel{\propto}{\rightarrow}$ third of these deaths will occur in developing countries. $^{5}$

The number of deaths from exposure to environmental tobacco smoke (ETS) in developing countries in not known, but in the응 United States is associated with about $3000^{\circ}$ deaths. ${ }^{6}$ Tobacco companies are intensifyingô their efforts through advertising to promoteo tobacco consumption, and this is particularly striking in developing countries. Research $\frac{\text { - }}{\sigma}$ shows that tobacco advertising reaches and 3 . influences young people. ${ }^{78}$

In Saudi Arabia several studies have been performed on smoking prevalence ando cigarette consumption among different sectors of the community. This research has been con-을. ducted under the auspices of many health and health-related organisations including the . Center for Research and Development, in the $N$ College of Applied Medical Sciences, at King N Saud Univerity in Riyadh, which partially sup-ত ported this study. Previous work investigatede smoking behaviour in Riyadh among university $\Phi$ students, ${ }^{3910}$ general secondary schools ? pupils, ${ }^{112}$ students in secondary health $\frac{0}{0}$ institutes, ${ }^{13}$ and among physicians. ${ }^{14}$ All these $\frac{\mathrm{O}}{\mathbb{Q}}$ studies showed that smoking, particularly ciga $-\frac{O}{D}$ rette smoking, is a substantial problem, which $\frac{\varrho}{9}$ is increasing in magnitude. In this study we surveyed the smoking behaviour of the Saudio adult population in Riyadh City, and investigated the factors associated with the uptake, continuation, and cessation of ${ }^{\risingdotseq}$ smoking.

Riyadh City is the capital of the Kingdom of Saudi Arabia, and is centrally located. The population of Riyadh is estimated to consist of 
1.2 million Saudi nationals and expatriates. The expatriates, who have different nationalities and religious and ethnic backgrounds, come to the Kingdom for employment. The Saudi nationals are all Moslems. Health services are free for all Saudis and non-Saudis working with the government.

The crude birth and death rates are 36 and 5 per 1000 persons, respectively. The infant and maternal mortality rates are 30 and 0.41 per 1000 live births, respectively. The adult literacy rate is $\mathbf{5 8 \%}$ and the annual per capita income is about US\$6200.

Tobacco control activities in the country at the present time are mostly individual efforts by many organisations and agents. These include health education messages in the media, smoking cessation clinics in some health services facilities, and legislation prohibiting smoking on government premises and tobacco advertising in all local mass media. A health warning on cigarette packages reads: "Smoking is a main cause of lung cancer, lung disease and heart and arterial disease."

\section{Subjects and methods}

Our target population was all adult Saudi nationals aged 15 years and older residing in Riyadh City. All Saudi families and individuals are required to register with the primary healthcare centre (PHCC) covering their residential areas. About $89 \%$ of all eligible individuals and families are registered with their designated primary healthcare centre. The rest receive healthcare in other health facilities run by their employers. No significant differences in demographics were found between the $11 \%$ who were not registered at the time of the study and the great majority who were registered.

In 1994 there were 58 PHCCs in Riyadh City; a random sample of 15 was chosen after stratification by the population density, socioeconomic status, and geographical location. The city was divided into five zones (north, south, east, west, and central). As the south and east zones contain almost twice the number of health centres as the north and west zones, four health centres were selected randomly from both the south and east zones, two centres were selected from both the north and west zones, and three were selected from the central zone.

By systematic random sampling, 105 Saudi subjects aged 15 years or older were drawn from the records of each of the selected PHCCs. Those individuals were then interviewed by trained male or female interviewers from the staff of each PHCC during their subsequent visits to the PHCC. Those who did not visit the PHCC during the study period were contacted and requested to visit the centre for the interview. The interview used a modified version of the standard World Health Organisation questionnaire for surveying smoking behaviour. ${ }^{15}$ The questionnaire consisted of 40 questions on sociodemographic variables; smoking behaviour; attitudes toward smoking; and the social, religious, health, and economic implications of smoking.
The questionnaire was pilot-tested and the wording and sequence of two questions were changed before it was administered. Data collection occurred from January to April 1994. Statistical analysis was done using the SAS statistical programme. The $\chi^{2}$ test was used to assess the significance of associations examined in this study.

For the purpose of this study, a current smoker was defined as any subject who had smoked any tobacco product daily for seven days or more and was still smoking at the time of the study. If such a subject was not smoking at the time of the study, he or she was considered to be an ex-smoker. Never-smokers are those who had never smoked before or had smoked in the past for less than seven days.

To minimise or eliminate non-response and under-reporting, anonymity of the respondents was maintained and no names were recorded. Subjects were informed that the information collected would be treated as confidential, that the data would be used only for research purposes, and that the data would be analysed only in the aggregate, and not at the level of the individual. The research assistants selected (men and women) were known to the subjects and were trusted by them.

\section{Results}

The study population consisted of 1534 subjects from the 15 selected PHCCs after 41 people $(2.6 \%$ of the total) were excluded because of incomplete or inconsistent data, or because of ineligibility due to age or nationality restrictions.

About $78 \%$ of the subjects were interviewed in the PHCCs during their subsequent visits and less than $22 \%$ were requested to visit the PHCC to complete the questionnaire. There were no significant differences in demographics between the two groups.

The sample selected was comparable to the population of Riyadh City in age and sex distribution, except for two differences by age group: (a) those above 60 years constituted less than $1 \%$ of our sample, although they represent about $4 \%$ of the general population of Riyadh, and (b) those 21-30 years of age comprised $43 \%$ of our sample whereas they accounted for an estimated $32 \%$ of the general adult population.

Table 1 presents data on smoking prevalence, intentions to smoke, age of smoking initiation, and reasons for smoking or not smoking, according to gender. Overall $25.3 \%$ were current smokers, $10.2 \%$ were ex-smokers, and $64.5 \%$ were never-smokers. The prevalence of former smoking, current smoking, and expected future smoking was significantly higher among men than among women. Most ever-smokers started smoking at ages $15-30$ years; significantly more men than women initiated smoking before the age of 15 years, whereas women were more likely than men to take up smoking after the age of 30 years.

The most important reasons for smoking among both men and women were psychological relief, boredom, and imitation of others 
Table 1 Subjects'smoking status, intentions to smoke in the future, age of smoking initiation, and reasons for smoking or not smoking, by gender (percentages)

\begin{tabular}{|c|c|c|c|}
\hline & Males & Females & Total \\
\hline Smoking status & $(n=828)$ & $(n=706)$ & \\
\hline Never-smokers & 44 & 88.5 & 64.5 \\
\hline Ex-smokers & 16 & 3.3 & 10.2 \\
\hline Current smokers & 40 & 8.2 & 25.3 \\
\hline \multicolumn{4}{|l|}{$\chi^{2}=322, \mathrm{df}=2, \mathrm{P}<0.0001$} \\
\hline Expected future smoking & $(\mathrm{n}=828)$ & $(\mathrm{n}=706)$ & \\
\hline Will smoke & 9.3 & 5.6 & 7.6 \\
\hline Will not smoke & 87.4 & 92.5 & 89.8 \\
\hline Do not know & 3.3 & 1.9 & 2.6 \\
\hline \multicolumn{4}{|l|}{$\chi^{2}=10.67, \mathrm{df}=2, P=0.004$} \\
\hline Áge of smoking initiation & $(n=464)$ & $(\mathrm{n}=81)$ & \\
\hline$<15$ years & 20.8 & 13.2 & 19.5 \\
\hline $15-30$ years & 78.6 & 80.9 & 79.1 \\
\hline $31-40$ years & 0.60 & 5.9 & 1.4 \\
\hline \multicolumn{4}{|l|}{$\chi^{2}=16.80, \mathrm{df}=2, P=0.004$} \\
\hline Reasons for smoking & $(n=464)$ & $(n=81)$ & \\
\hline Imitation & 10.6 & 12.9 & 10.8 \\
\hline Psychological relief & 30.1 & 34.3 & 30.8 \\
\hline Relatives/friends' pressure & 5.7 & 4.3 & 5.3 \\
\hline Boredom & 20.3 & 25.7 & 21.3 \\
\hline Work pressures & 11.9 & 1.4 & 10.3 \\
\hline All or some of the above & 13.0 & 5.7 & 11.9 \\
\hline Others & 8.4 & 15.7 & 9.5 \\
\hline \multicolumn{4}{|l|}{$\chi^{2}=15.50, \mathrm{df}=6, \mathrm{P}=0.011$} \\
\hline Reasons for not smoking & $(n=364)$ & $(\mathrm{n}=625)$ & \\
\hline Health considerations & 11.8 & 24.1 & 19.6 \\
\hline Religious considerations & 30.0 & 42.1 & 37.6 \\
\hline Social considerations & 5.6 & 4.4 & 5.7 \\
\hline Financial factors & 1.9 & 1.4 & 1.6 \\
\hline All or some of the above & 47.5 & 27.5 & 34.9 \\
\hline Others & 3.2 & 0.5 & 1.5 \\
\hline$\chi^{2}=66.31, \mathrm{df}=5, \mathrm{P}=0.001$ & & & \\
\hline
\end{tabular}

Table 2 Smoking prevalence among the study subjects, according to marital status and education

\begin{tabular}{|c|c|c|c|c|c|c|c|c|}
\hline & \multicolumn{8}{|c|}{ Smoking status } \\
\hline & \multicolumn{2}{|c|}{ Never-smokers } & \multicolumn{2}{|c|}{ Ex-smokers } & \multicolumn{2}{|c|}{ Current smokers } & \multicolumn{2}{|l|}{ Total } \\
\hline & $n$ & $\%$ & $n$ & $\%$ & $n$ & $\%$ & $n$ & $\%$ \\
\hline \multicolumn{9}{|l|}{ Marital status } \\
\hline Married & 623 & 67 & 99 & 11 & 210 & 22 & 932 & 100 \\
\hline Single & 306 & 59 & 55 & 11 & 159 & 30 & 520 & 100 \\
\hline Divorced & 39 & 69 & 1 & 2 & 16 & 29 & 56 & 100 \\
\hline Widowed & 21 & 81 & 1 & 4 & 4 & 15 & 26 & 100 \\
\hline \multicolumn{9}{|c|}{$\begin{array}{l}\chi^{2}=20.9951, \mathrm{df}=6, \mathrm{P}=0.01 \\
\text { Education }\end{array}$} \\
\hline Illiterate & 118 & 81 & 12 & 8 & 16 & 11 & 146 & 100 \\
\hline Read/write & 89 & 70 & 12 & 9 & 27 & 21 & 128 & 100 \\
\hline Elementary & 99 & 65 & 19 & 12 & 35 & 23 & 153 & 100 \\
\hline Intermediate & 208 & 64 & 20 & 6 & 99 & 30 & 327 & 100 \\
\hline Secondary & 267 & 59 & 48 & 11 & 136 & 30 & 451 & 100 \\
\hline University + & 208 & 63 & 45 & 14 & 76 & 23 & 329 & 100 \\
\hline \multicolumn{9}{|c|}{$\chi^{2}=41.2645, \mathrm{df}=10, \mathrm{P} \leq 0.001$} \\
\hline
\end{tabular}

Table 3 Reasons for not smoking among never-smokers, for quitting among ex-smokers, and for attempting to quit or thinking about quitting among current smokers (percentages)

\begin{tabular}{lccccc}
\hline & \multicolumn{5}{c}{ Smoking status } \\
\cline { 2 - 5 } Reason & $\begin{array}{l}\text { Never-smokers } \\
(n=989)\end{array}$ & $\begin{array}{l}\text { Ex-smokers } \\
(n=156)\end{array}$ & $\begin{array}{l}\text { Current smokers } \\
(n=389)\end{array}$ & $\chi^{2}$ & $P$ \\
\hline Religious & 45.4 & 40.8 & 21.7 & 66.88 & $<0.001$ \\
Health & 15.7 & 22.5 & 40.7 & 99.0 & $<0.001$ \\
Social & 5.4 & 5.4 & 3.3 & 2.51 & 0.205 \\
Financial & 1.8 & 4.8 & 1.1 & 10.03 & 0.006 \\
All or some of the above & 30.5 & 24.5 & 32.3 & 4.14 & 0.126 \\
Others & 1.3 & 2.0 & 0.9 & 0.76 & 0.706 \\
\hline
\end{tabular}

$\star$ Two degrees of freedom.

(table 1). Men gave significantly more weight to work pressures as a reason for smoking than women. The most important reasons for not smoking among both sexes were religious and health considerations, with women giving these factors significantly more weight than men. Financial factors were cited by very few respondents as a reason for not smoking.
Table 2 shows smoking prevalence according- -1 to marital status and educational level. Widowed subjects were less likely to be current? smokers and more likely to be never-smokers compared with those in other marital categories. Single subjects were more likely to $\overrightarrow{\vec{F}}$ be ever-smokers $(41 \%)$ than those who were or had been married $(19 \%, 31 \%$, and $33 \%$ for widowed, divorced, and married subjects, $\overline{\bar{c}}$. respectively). Smoking prevalence was signifi- $\widehat{\varnothing}$ cantly higher among literate subjects $(21 \%$ to $30 \%$ ) than among those who were illiterate $(11 \%)$. Other factors studied, such as income $\overrightarrow{0}$ and place of residence, were not significantly associated with smoking prevalence.

Cigarettes were the most important form of tobacco used for all subjects. The average duration of smoking for all smokers was 11.2 years. The average daily cigarette consumption $\vec{ज}$ was 18 , with men consuming significantly응 more than women (20 and five cigarettes perday, respectively). There were no other signifi- $\infty$ cant associations between daily cigarette $\frac{\mathbb{O}}{\mathscr{P}}$ consumption and the other demographic, $\frac{\mathbb{D}}{3}$ socioeconomic, or geographical characteristics of the studied subjects.

Compared with the previous year, daily ciga- $\vec{c}$ rette consumption had increased for $28.7 \%$ of current smokers, had decreased for $22.2 \%$, and had remained the same for $49.1 \%$. These figures did not differ significantly amongo smokers when stratified by demographic, socioeconomic, and geographical variables.

The reasons for not smoking amongo $\overrightarrow{\overline{\hat{O}}}$ never-smokers, for quitting among ex-smokers, and for attempting to quit or thinking about quitting among current smokers, are shown intable 3. Religious and health considerationso were the most important reasons for all threes categories of respondents. Current smokers, however, gave significantly more weight to health considerations than did never-smokers and former smokers, whereas never-smokers 음 and former smokers gave religious considera- $\frac{\bar{\sigma}}{3}$ tions significantly more weight than didi current smokers. Financial and social considerations were of minimal importance to all three smoking categories, but ex-smokers give financial concerns slightly (but signifi=o cantly) more weight than never-smokers and current smokers. Education, income, and placeos of residence in Riyadh were not significantlyr related to the reasons for smoking, not smoking, or attempting to quit.

More than $98 \%$ of both men and women said that smoking has adverse effects on health, but this belief was significantly more common ${ }^{\text {? }}$ among those who were more than 20 years of age compared with younger persons $(P=$ 0.017).

Religious men and physicians wereo considered to be the most effective anti-smoking advocates by $44 \%$ of respond- 8 ents. Health educators, nurses, social workers? and teachers were cited by less than $5 \%$ of theo sample as effective anti-smoking agents.

Almost two-thirds (66.4\%) of the study population said that the warning on cigarettes packages is not deterring people from smoking, and women are more likely than men to hold 
Table 4 Proportion of subjects (\%) supporting various anti-smoking measures ( $n=1534)$, by smoking status

\begin{tabular}{|c|c|c|c|c|c|c|c|c|c|}
\hline & \multicolumn{9}{|c|}{ Smoking status } \\
\hline & \multicolumn{3}{|c|}{ Never-smokers $(n=989)$} & \multicolumn{3}{|c|}{ Ex-smokers $(n=156)$} & \multicolumn{3}{|c|}{ Current smokers $(n=389)$} \\
\hline & Agree & $\begin{array}{l}\text { Don't } \\
\text { agree }\end{array}$ & $\begin{array}{l}\text { Don't } \\
\text { know }\end{array}$ & Agree & $\begin{array}{l}\text { Don't } \\
\text { agree }\end{array}$ & $\begin{array}{l}\text { Don't } \\
\text { know }\end{array}$ & Agree & $\begin{array}{l}\text { Don't } \\
\text { agree }\end{array}$ & $\begin{array}{l}\text { Don't } \\
\text { know }\end{array}$ \\
\hline Increase price & 92 & 5 & 4 & 69 & 26 & 5 & 35 & 49 & 16 \\
\hline Stop imports & 89 & 5 & 6 & 69 & 25 & 6 & 60 & 36 & 4 \\
\hline No advertising & 95 & 3 & 2 & 90 & 6 & 4 & 89 & 6 & 5 \\
\hline Legislation & 82 & 10 & 8 & 65 & 29 & 6 & 53 & 41 & 6 \\
\hline Educational pamphlets & 89 & 5 & 6 & 89 & 3 & 8 & 93 & 6 & 1 \\
\hline Anti-smoking TV shows & 91 & 6 & 3 & 80 & 18 & 2 & 80 & 15 & 5 \\
\hline Stop shop sales & 90 & 9 & 1 & 54 & 36 & 10 & 35 & 67 & 8 \\
\hline Informing students & 97 & 2 & 1 & 90 & 3 & 7 & 80 & 9 & 11 \\
\hline Religious teaching & 98 & 1 & 1 & 70 & 10 & 20 & 71 & 16 & 13 \\
\hline
\end{tabular}

that belief $(P<0.001)$. Less than a third of those who agreed that the warning is deterring smoking said that this effect is strong or very strong; subjects who were female, single, more highly educated, and had a higher income were more likely to believe that the warning had a strong deterrent effect $(P=0.035)$.

Most never-smokers (82-97\%) supported all the tobacco control strategies presented to them in the survey, particularly religious and educational messages. Current and former smokers, however, were more supportive of educational messages and advertising bans than of other strategies, such as legislation, price increases, and curbs on imports and shop sales (table 4 ).

\section{Discussion}

The findings of this study show that smoking in Riyadh City among the Saudi population is an important problem. Current and former smoking prevalence is much higher among men than among women (see table 1). Previous studies of Saudi smoking behaviour have generally reported similar findings, with smoking prevalence at $24-47 \%$ among men and only $12 \%$ among women ${ }^{39101213}$ in the young populations surveyed.

Varying smoking prevalence rates have been reported for developed and developing countries. In most Western countries the percentage of adult men who smoke is in the low 30s. Smoking prevalence is lower for women but the decline in smoking is slower among women than among men. The narrowing gap in smoking prevalence between men and women is due, in part, to higher rates of smoking uptake among less educated young women. ${ }^{16-18}$ In developing countries among young adults, the prevalence of current smoking, former smoking, and never-smoking was $20-48 \%, 6-27 \%$, and $32-51 \%$, respectively. $^{19}$

The general pattern of lower smoking prevalence and lower daily cigarette consumption among women is reported for almost all developing societies. This may be related to social, cultural, and religious factors, and the financial dependence of women on men. However, smoking surveys among women in developing countries and Arab and Moslem countries in particular may be less accurate because some smoking women may deny the practice where it is still socially unacceptable. This may explain the $0 \%$ smoking prevalence reported for women in a university community in Iraq. ${ }^{20}$

Smoking initiation tends to occur rather early in life. In our study most male and female smokers started smoking before the age of 21 . Other studies of students in Riyadh have shown that about $40-90 \%$ initiated smoking somewhat earlier, before the age of 16 years. ${ }^{30-13}$ Studies from developed countries show that smoking uptake usually occurs before the age of 17 years $^{82122}$; for Arab and other developing countries the situation is similar.

Recent reports provide convincing evidence that tobacco use is a paediatric epidemic. ${ }^{23}$ Some studies have shown that those who initiated smoking at younger ages were more likely to continue smoking ${ }^{24}$ whereas others have found the opposite. ${ }^{22}$

Smokers in our study consumed an average of 18 cigarettes per day ( 20 for men and five for women). Previous studies of students in the Kingdom have reported an average daily cigarette consumption of 14 and five cigarettes for men and women, respectively. ${ }^{3913}$

We found that religious considerations were much more important reasons for not smoking among never-smokers and former smokers, whereas health considerations were much more important reasons for attempting to quit among current smokers. Religious teaching prohibits or at least strongly discourages smoking. Those who adhere to religious teaching tend to avoid smoking from the start. Those who smoke are probably less religious, and hence religious considerations may not be the most important motives for quitting; rather, health issues appear to be much more important to them. Financial considerations were not important influences on smoking behaviour in the Kingdom (although they are important in affecting smoking behaviour in some countries ${ }^{10}$ ). This is probably because cigarettes in Saudi Arabia cost about US $\$ 1$ for a pack of 20 cigarettes, and the average per capita daily income is more than US\$17, compared with Sudan, for example, where the price of cigarettes is similar but where the average per capita daily income is only about US $\$ 1.5$.

The higher smoking prevalence found among the more highly educated and those with a higher income was not unexpected. The experience in developed countries has shown that before anti-smoking campaigns begin in a community, higher social classes smoke more 
than lower classes as smoking is considered to be a symbol of elevated social status and prestige. After anti-smoking campaigns begin, smoking prevalence drops more among higher social classes, apparently because they are more likely to receive and accept anti-smoking messages. ${ }^{25}$ Some studies have reported a stronger effect of income and education on smoking prevalence among men compared with women. ${ }^{26}$

Only $11 \%$ of our study population said that the warning on cigarette packages is strongly deterring people from smoking. The accumulated evidence suggests that current tobacco warnings on cigarettes packages and advertisements have, at best, a limited effect in communicating the hazards of smoking in countries such as the United States, where most smokers are unfamiliar with even the general themes of the health messages. ${ }^{27} 28$ However, warnings that are novel, targeted, and developed through a creative process function more effectively as communicating devices. ${ }^{27}$

A combination of educational, environmental, and legislative strategies are important to assure the success of tobacco control activities. If the results of this study are replicated in other areas of the country, then anti-smoking campaigns should actively involve religious teaching, which prohibits or strongly discourages smoking. Physicians can play a significant role, particularly in primary health care settings, by enquiring about tobacco use and explaining the health consequences of smoking and exposure to environmental tobacco smoke. Teachers can have a major impact because they reach a large number of individuals at risk, who may respond more attentively to teachers than to others.

Health educators are very few in number and many lack proper training and adequate resources. We expect that they will play an effective role in tobacco control when these deficiencies are corrected. That is the task of the next phase of this continuing research project. Action is required now if we are to prevent or at least control the expected future epidemic of smoking-related health problems in Saudi Arabia. This research was partly funded by the Center for Research and
Development in the College of Applied Medical Sciences of King Saud University in Riyadh. The help offered by the research assistants in collecting the data is greatly appreciated.

1 World Health Organisation. The tobacco epidemic: A global public health emergency. Tobacco alert, World No-Tobacco Day, 1996 Special Issue: 1-28.
2 Slama K, ed. Tobacco and health. Proceedings of the ninth world -1 conference on tobacco and health, 10-14 October 1994, New York: Plenum Press, 1995.

3 Saeed A. Smoking habits of students in the college of Allieb? Medical Sciences, Riyadh. $\mathcal{F} R$ Soc Health 1987;5:187-8. 글

4 Arabi M. Women's smoking habits in the Sudan. In Abstracts of the seventh world conference on tobacco and health Perth, Western Australia, 1990:150.

5 World Health Organisation. Tobacco alert. Geneva: WHOS Programme on Tobacco or Health, 1991.

6 US Environmental Protection Agency. Respiratory healt effects of passive smoking: lung cancer and other disorders Washington, DC: US Environmental Protection Agency, 1992. (EPA/600/6-90/006F)

7 Amos A. Cigarette advertising and marketing strategies Tobacco Control 1992;1:3-4.

8 US Department of Health and Human Services. Preventing tobacco use among young people. A report of the Surgeon Geno eral Atlanta, Georgia: Public Health Service, Centers for Disease Control and Prevention, Office on Smoking and Health, 1994 (US Government Printing Office No S/ 017-001-00491-0.)

9 Taha A, Bener A, Noah M, Saeed A, Al Harthy S. Smoking habits of King Saud University Students in Riyadh. Ann Saudi Med 1991;11:141-3.

10 Jarallah J. Smoking habits of medical students at King Saud University, Riyadh. Saudi Med F 1992;13:510-3.

11 Rowlands D, Shpster P. Cigarette smoking among 11-120 year old school boys. Saudi Med F 1987;6:613-8.

12 Felimban F, Jaralla J. Smoking habits of secondary school boys in Riyadh, Saudi Arabia. Saudi Med F 1994;15:438 42 .

13 Saeed A, Al Johali E, Al Shahri A. Smoking habits of students in secondary health institutes in Riyadh City Saudi Arabia. $\mathcal{F} R$ Soc Health 1993;111:132-5.

14 Saeed A, Taha A, Al Shahri A. Smoking habits of physicians in Riyadh, Saudi Arabia. Saudi Med f 1989;10:508-11.

15 World Health Organisation. Guidelines for the conduct ob tobacco smoking among health professionals. Geneva: Worlकb Health Organisation, 1984. (WHO document WHO/SMO 84.)

16 Pierce J. International comparisons of trends in cigarett smoking prevalence. Am f Public Health 1989;79:152-7.

17 Pierce JP, Fiore MC, Novotny TE, et al. Trends in cigarette smoking in the United States-educational differences ar increasing. $\mathcal{F A M A} 1989 ; 261: 40-56$.

18 Chollat-Tarquet C. Women and tobacco. Geneva: World Health Organisation, 1992:9-12.

19 Masironi R, Rothwell K. Smoking in developing countrie (III). Geneva: World Health Organisation, 1985:19-33(WHO document WHO/SMO/85.1.)

20 Abed J, Al Dabbagh S, Khalil H, Selevany B. Cigarette smoking: epidemiology and effects of some cardiovascular parameters in medical students. Ann Cll Med Mosul 1988 14:37-9.

21 Older J. Antismoking language that the young caro understand. World Health Forum 1986;7:74-8.

22 Glover E, Laflin M, Edwards S. Age of initiation of and switching patterns between smokeless tobacco and ciga

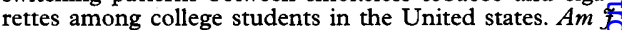
Public Health 1989;79:207-8.

23 Perry CL, Eriksen M, Giovino G. Tobacco use: a pediatrie epidemic. Tobacco Control 1994;3:97-8.

24 US Department of Health, Education, and Welfare Smoking and health. A report of the Surgeon General, 1979 Rockville, Maryland: Public Health Service, Office or Smoking and Health, 1979 (DHEW Publication NO (PHS) 79-50066.)

25 Saeed A, Taha A. Comparative study of the smoking habit of physicians in Cairo and Riyadh in 10 years. Saudi Med 1991;12:343-4.

26 Tuomilehto J, Zimmet $\mathrm{P}$, Taylor $\mathrm{R}$, et al. Smoking rates iro Pacific Islands, Bull WHO 1986;64:447-56.

27 Fischer PM, Krugman DM, Fletcher JE, Fox RJ, Rojas THO An evaluation of health warnings in cigarette advertise ments using standard market research methods: what does it mean to warn? Tobacco Control 1993;2:279-85.

28 Richards JW, Fischer PM, Conner FG. The warning cigarette packages are ineffective. $\Im A M A$ 1989;261:45 